ISSN 1518-3483

Licenciado sob uma Licença Creative Commons

\title{
Casas familiares rurais e desempenho escolar: um estudo na região sudoeste do Paraná
}

\author{
Rural family houses and school performance: \\ a research in the southwest region of Paraná
}

\section{Edival Sebastião Teixeira ${ }^{[a]}$, Letícia Cristina Antunes ${ }^{[\mathrm{b}]}$}

[a] Doutor em Psicologia da Educação pela Universidade de São Paulo (USP), coordenador do Programa de Pós-Graduação em Desenvolvimento Regional da Universidade Tecnológica Federal do Paraná (UTFPR), Curitiba, PR - Brasil, e-mail: edival@utfpr.edu.br

[b] Estudante de Graduação em Letras Português Inglês na Universidade Tecnológica Federal do Paraná (UTFPR), Curitiba, PR - Brasil, e-mail: leticristina.a@gmail.com

\section{Resumo}

O artigo resulta de pesquisa ampla que teve por objetivo compreender a relação entre a educação do campo, na perspectiva da pedagogia da alternância praticada pelas casas familiares rurais da região sudoeste do Paraná, e o desenvolvimento sustentável da agricultura familiar. Neste texto são priorizados dois aspectos da pesquisa: a relação das casas familiares com a 
escola pública e uma caracterização dos seus corpos docentes, sobretudo, em relação à formação e tempo de experiência profissional com a pedagogia da alternância e possíveis repercussões de ambos os aspectos no desempenho escolar dos seus alunos. Os dados foram obtidos mediante entrevista, questionários e observação. Os resultados sugerem que essas instituições se consolidaram como alternativa para a educação escolar dos filhos de pequenos agricultores, ainda que tenham problemas de natureza administrativa que dificultam muito a manutenção de um corpo docente estável, seja em função do vínculo precário da maioria dos professores da rede estadual, seja em função da rotatividade dos monitores causada por questões salariais.

Palavras-chave: Casa familiar rural. Pedagogia da alternância. Desempenho escolar.

\section{Abstract}

The paper is the result of a research which aimed at understanding the relationship between the rural education, in the perspective of the alternation pedagogy practised by the rural family houses of the Southwest Region of Paraná, and the sustainable development of familiar agriculture. This text is prioritized two aspects of the research: the relationship between rural family houses and the public school and a characterization of its faculty, particularly in regard to training and professional experience with the alternation pedagogy and the possible impacts of both aspects in students' education. The data were collected through interviews, questionnaires and observation. The results suggest that these institutions have been consolidated as an alternative to school education of the children of small farmers, even if they have problems of administrative nature that make it very difficult to maintain a stable teaching staff, either because of the precarious relationship of the majority of teachers with the State, whether as a result of the rotation of monitors due to salary issues.

Keywords: Rural family houses. Alternation pedagogy. School performance.

\section{Introdução}

Casas familiares rurais (CFRs) são instituições de ensino que se originaram em meados da década de 1930 na França, com o objetivo de 
propiciar uma educação escolar mais adaptada à realidade dos filhos de pequenos agricultores franceses de então, de modo que os jovens pudessem frequentar a escola sem se afastar do trabalho na propriedade da família. Ao mesmo tempo em que se buscava um ensino capaz de prover uma formação profissional mais apropriada à realidade do campo, procurava-se incentivar a permanência do jovem na sua própria região, criando alternativas de trabalho e renda (TEIXEIRA; BERNARTT; TRINDADE, 2008).

O método que viabilizava tanto a frequência aos estudos quanto a atividade agrícola, consistia em os jovens permanecerem parte do tempo na escola, onde tinham aulas com um técnico agrícola, e parte em casa, onde as próprias famílias eram responsáveis por acompanhar suas atividades.

A experiência inicial francesa foi muito bem-sucedida e após a segunda Guerra Mundial começa a chamar atenção como alternativa para a educação do campo e se expande para outros países. No Brasil, a experiência começou em 1969 no Estado do Espírito Santo, onde foram construídas as três primeiras "Escolas Famílias Agrícolas", a partir de uma forma de organização da alternância surgida na Itália.

Na região Sul do Brasil seguiu-se o modelo francês das casas familiares rurais, tendo a primeira CFR surgido em 1987 na zona rural do município de Barracão (atualmente faz parte do município de Bom Jesus do Sul), no extremo sudoeste paranaense, na fronteira com a província argentina de Misiones; a mais recente iniciou suas atividades em 2010, no município de Realeza. Em todo o Estado do Paraná existem atualmente 42 CFRs, das quais 17 estão instaladas na região sudoeste. Todas essas instituições fazem parte da Associação das Casas Familiares Rurais do Sul do Brasil (Arcafar/Sul) e todas utilizam o modelo da pedagogia da alternância.

A pedagogia da alternância que se pratica nas casas familiares rurais assenta-se em quatro princípios:

1) o próprio método da alternância;

2) a ênfase na formação integral do jovem;

3) a participação das famílias na condução do projeto educativo e na gestão da escola; 
4) o desenvolvimento do meio. Por conseguinte, preconiza que se deve levar em conta a realidade das propriedades rurais e das comunidades dos alunos, com o intuito de identificar possibilidades para o desenvolvimento sustentável das propriedades, o que implica, por sua vez, a permanência dos jovens no campo.

O método da alternância na educação do campo encontra-se bastante difundido no Brasil e tem, inclusive, respaldo legal. A Lei de Diretrizes e Bases da Educação Nacional, em seu artigo 23, abre várias possibilidades para a organização da educação básica, tais como a seriação anual, a periodização semestral, a alternância regular de períodos de estudos, dentre outras, sempre que o interesse do processo de aprendizagem assim o recomendar. No artigo 28 dessa mesma lei, lê-se que a oferta da educação básica para a população rural deverá levar em conta as peculiaridades da vida nesse contexto, inclusive no que diz respeito à adequação do calendário escolar à sazonalidade da agricultura (BRASIL, 1996).

Portanto, do ponto de vista legal são esses dispositivos que têm sido invocados para justificar e defender a legalidade da alternância de tempos e espaços escolares perante os sistemas de ensino. Contudo, é necessário diferenciar entre a possibilidade legal de se alternarem tempos e espaços de formação e pedagogia da alternância enquanto método pedagógico. Aquela pode subsistir sem esta, mas esta, de modo algum pode prescindir daquela.

De fato, a alternância de tempos e espaços pode ser utilizada em qualquer nível de ensino e com qualquer pedagogia enquanto teoria da educação. Isto é, com qualquer método pedagógico. Já a pedagogia da alternância, por sua vez, consiste num método pedagógico cuja alternância de tempos e espaços é apenas uma condição necessária, porém não suficiente.

Por pedagogia da alternância compreendemos uma metodologia de organização do ensino escolar que conjuga diferentes experiências formativas distribuídas ao longo de tempos e espaços distintos, tendo como finalidade uma formação profissional. 
Os espaços dizem respeito aos locais onde a formação se processa: escola (no Paraná são as Casas Familiares Rurais), indústria, propriedade agrícola, comércio, etc. Os tempos dizem respeito aos períodos de permanência dos estudantes nesses espaços. Em quaisquer dos espaços a formação é experimentada em tempo integral, tendo-se como pressuposto a necessária articulação entre educação e trabalho, teoria e prática, de modo que se favoreça ao educando meios para a reflexão acerca de suas próprias experiências formativas.

Assim, na pedagogia da alternância procura-se articular os diferentes espaços e tempos formativos, alternando momentos de atividade no meio socioprofissional do educando e momentos de atividade escolar propriamente dita, nos quais se focaliza o conhecimento acumulado, considerando sempre as experiências concretas dos alunos. De acordo com Silva (2006, p. 6), a alternância, enquanto princípio pedagógico, vai além de meras sucessões de tempos e espaços porque "visa desenvolver na formação dos jovens situações em que o mundo escolar se posiciona em interação com o mundo que o rodeia”.

A pedagogia da alternância enfatiza a participação das famílias e das comunidades na condução do projeto pedagógico e na própria gestão da escola. Portanto, trata-se mais do que uma simples modalidade de organização da escolarização que alterna tempos e espaços para favorecer o ajuste do calendário escolar ao calendário agrícola no contexto da educação do campo. Na verdade, consiste em uma pedagogia que se sustenta na concepção de que a formação resulta de um processo interativo entre o sujeito e os seus contextos: familiar, profissional, político, cultural, escolar, etc., processo esse mediado pelo conhecimento acumulado historicamente.

No que diz respeito aos fundamentos da educação, o método da alternância enfatiza a necessidade de romper com formas de ensino baseadas na transmissão vertical de conhecimentos, partindo-se do pressuposto de que "o conhecimento deve ser construído na interação das pessoas entre si e das pessoas com o meio onde estão inseridas" (BEGNAMI, 2006, p. 32). Por conseguinte, considera-se que cada elemento contextual 
tem uma característica formativa. Todavia, na pedagogia da alternância toma-se como pressuposto que o jovem seja o principal ator de sua formação. Por essa razão, a concepção de aprendizagem do método está próxima das abordagens conceituais de autores como Jean Piaget, Paulo Freire e Edgard Morin; David Kolb e Dermeval Saviani (BEGNAMI, 2006; GIMONET, 1999), além de outros estudiosos do campo educacional como Mikhail Pistrak e de Lev Vigotski, ainda que esses diversos autores não necessariamente compartilhem dos mesmos pressupostos teórico-metodológicos (TEIXEIRA; COSTA; PERUZO, 2007).

De acordo com Begnami (2006, p. 36), nesse método "o processo de aprendizagem opera a partir da realidade observada e refletida e a ela retorna com o compromisso de intervir e buscar soluções para os problemas que a realidade apresenta". Ou seja, nessa metodologia parte-se da experiência concreta do educando, problematiza-se e reflete-se sobre sua realidade, com a finalidade de a mesma voltar para transformá-la. Decorre daí que um dos principais fundamentos da pedagogia da alternância consista justamente na articulação entre teoria e prática, como condição necessária para a formação do sujeito.

Face o exposto, pode-se inferir que a ação pedagógica no contexto da pedagogia da alternância impõe expressivas exigências ao corpo docente. Exigências tais que se consubstanciam em sólida formação teórico-metodológica e em experiência profissional, tanto no que diz respeito aos fundamentos e à prática da educação em geral, quanto aos fundamentos e à prática do método em questão.

O presente trabalho resulta de uma pesquisa mais ampla, desenvolvida no âmbito do Programa de Pós-Graduação em Desenvolvimento Regional da Universidade Tecnológica Federal do Paraná, que tem por objetivo compreender a relação entre a educação do campo, na perspectiva da pedagogia da alternância praticada pelas casas familiares rurais da região sudoeste do Paraná, e o desenvolvimento sustentável da agricultura familiar. Neste artigo, especificamente, são priorizados dois aspectos da pesquisa: a relação das CFRs com a escola pública e uma caracterização dos seus corpos docentes, sobretudo, em relação à formação e tempo de 
experiência profissional com a pedagogia da alternância e possíveis repercussões de ambos os aspectos no desempenho escolar dos seus alunos.

\section{Metodologia}

Os dados foram obtidos mediante entrevistas abertas realizadas com as equipes de coordenação das CFRs, por meio de questionários aplicados às equipes de coordenação, a professores e monitores, bem como a partir de observações realizadas às instituições e a propriedades rurais.

Nas entrevistas abertas procurou-se compreender a dinâmica das casas familiares rurais, principalmente no tocante à aplicação de sua metodologia de ensino, ao perfil dos alunos, à visão dos professores e monitores sobre o trabalho desenvolvido, ao desempenho acadêmico dos estudantes, aos procedimentos das visitas domiciliares que os monitores realizam aos alunos e suas famílias, às ações desenvolvidas pela CFR com as famílias e ao modo como os alunos estão aplicando o conhecimento adquirido em suas propriedades.

Por meio dos questionários respondidos pelas equipes das CFRs buscou-se precisar os dados em relação ao número de alunos, funcionários, às associações locais de apoio de cada CFR, à infraestrutura, aos serviços e ações desenvolvidas com as famílias, aos projetos de vida dos alunos e sobre a relação entre as casas familiares rurais e a escola pública.

Quanto aos professores e monitores, os questionários visavam a levantar dados sobre a formação escolar, idade, tempo de experiência em educação, sobretudo com pedagogia da alternância, bem como de suas concepções sobre desenvolvimento sustentável, educação, educação do campo, pedagogia da alternância, relações entre educação e trabalho, relações entre pedagogia da alternância e agricultura familiar e em relação ao meio ambiente.

Ressalta-se que a participação dos sujeitos era livre, sendo todos informados acerca dos objetivos e procedimentos da pesquisa, e os que concordaram em participar assinaram um Termo de Consentimento Livre e Esclarecido. 


\section{As casas familiares rurais e a escola pública no Paraná}

No Estado do Paraná as CFRs estão ligadas a alguma escola estadual, que é denominada Escola Base, a qual cede os professores para as áreas do currículo oficial do ensino fundamental ou médio, conforme o caso. Por sua vez, os conteúdos específicos da formação oferecida pelas CFRs são ministrados por docentes contratados pela Associação das Casas Familiares Rurais do Sul do Brasil, os quais têm formação superior em áreas afins com a agricultura, tais como agronomia, medicina veterinária, administração rural, zootecnia, nutrição; ou ainda têm formação de nível médio em áreas de interesse para as CFRs. Todos esses docentes que não pertencem à rede estadual são chamados de monitores.

O monitor acompanha, anima, dinamiza todas as atividades desenvolvidas na CFR e no meio socioprofissional tendo o compromisso de fazer com que todos os atores (alunos, famílias, lideranças comunitárias, profissionais e instituições) interajam na formação integral do jovem.

Os professores participam de todas as atividades na CFR e, por isso, também acompanham os monitores nas visitas que os mesmos realizam periodicamente às propriedades das famílias dos alunos, fato esse que contribui de maneira decisiva para a aproximação entre professores/ escola e famílias e, por extensão, para o controle social da qualidade da educação oferecida por essas instituições.

São as Escolas Base que gerenciam a vida acadêmica dos jovens que frequentam as CFRs do Paraná e que, ao fim de seus cursos, os certificam. Dessa forma, os alunos dessas instituições são alunos da rede pública estadual para todos os efeitos legais.

Por meio do Decreto n. 3.106/94, de 14 de março de 1994, o governo do Estado do Paraná aprovou o "Programa das Casas Familiares Rurais" ao mesmo tempo em que determinou às Secretarias de Estado envolvidas a tomada das medidas necessárias à implantação e continuidade do projeto (PARANÁ, 1994). A partir de então se firmou um convênio de cooperação técnica e financeira entre a Secretaria de Estado da Educação do Paraná (Seed) e a Arcafar/Sul, mediante o qual o Estado assume parte 
dos encargos financeiros e os encargos legais decorrentes da escolarização em nível fundamental e/ou médio proporcionada pelas CFRs. No âmbito dos Núcleos Regionais de Educação foram criados setores de acompanhamento e assessoria pedagógica, bem como de certificação (GOWACKI; BERNARTT; TEIXEIRA, 2007).

Todavia, se por um lado o convênio contribuiu significativamente para a sustentação financeira da CFR, por outro criou alguns constrangimentos tendo em vista as importantes diferenças existentes entre a rigidez organizacional e pedagógica da escola pública e o modo de organização, constituição, gestão e prática pedagógica das casas familiares rurais. A situação criada, pois, decorria da necessidade de "encaixar" um projeto pedagógico pensado em moldes muito distintos, e em certo sentido avançado, em uma estrutura pedagógica rígida.

Não foi sem resistência que o Conselho Estadual de Educação acatou a proposta da pedagogia da alternância. Isso a despeito de a LDB em seu artigo 23 abrir várias possibilidades para a organização da educação básica, tais como a seriação anual, a periodização semestral, a alternância regular de períodos de estudos, dentre outras, sempre que o interesse do processo de aprendizagem assim o recomendar; e ainda que no artigo 28 dessa mesma norma se leia que a oferta da educação básica para a população rural deverá levar em conta as peculiaridades da vida nesse contexto, inclusive no que diz respeito à adequação do calendário escolar à sazonalidade da agricultura.

Vencidas as resistências iniciais, atualmente os professores das Escolas Base cedidos pela Seed desenvolvem suas atividades em regime de dedicação exclusiva à CFR à qual estão ligados. Assim, considerando que as turmas nessas instituições nunca têm mais do que 25 alunos e que cada CFR geralmente não tem mais do que três turmas, cada professor tem, no máximo, um número próximo de 75 alunos por ano letivo. Acrescente-se ainda que, diferentemente dos professores urbanos, esses docentes não precisam mudar de turmas, ou até mesmo de escola, a cada curto período de uma ou duas aulas, ou ainda ter de fazer duplas ou triplas jornadas para dar conta da preparação de aulas e da correção de provas, por exemplo. 
Dessa forma, além da relativa segurança que a dedicação exclusiva possibilita ao docente, essa situação sui generis para as escolas de educação básica públicas tem permitido um atendimento quase personalizado aos jovens que frequentam as CFRs paranaenses, particularmente das localizadas na região sudoeste.

\section{Caracterização das casas familiares rurais da região sudoeste do Paraná}

As CFRs do sudoeste do Paraná estão localizadas nos seguintes municípios: Bom Jesus do Sul, Capanema, Chopinzinho, Coronel Vivida, Dois Vizinhos, Enéas Marques, Francisco Beltrão, Manfrinópolis, Marmeleiro, Nova Prata do Iguaçu, Pato Branco, Pérola do Oeste, Santa Izabel do Oeste, São Jorge do Oeste, Santo Antônio do Sudoeste, Sulina e Realeza. A CFR desse último município não foi envolvida na pesquisa tendo em vista que iniciou suas atividades depois que a investigação já estava em andamento.

As 16 CFRs da região sudoeste do Paraná pesquisadas ministram cursos de ensino fundamental (EF) e ensino médio (EM), nos quais, além dos conteúdos curriculares da base nacional, os jovens estudam outros conteúdos apropriados para a atividade na agricultura. Em algumas instituições os cursos de EM são técnico-profissionalizantes, ao passo que em outras tanto os cursos de EF quanto os de EM são genericamente denominados como cursos de qualificação em agricultura.

As CFRs participantes da pesquisa tinham um total de 835 alunos no ano letivo de 2010, sendo 645 meninos e 190 meninas; e 1.715 egressos, sendo 1.233 meninos e 482 meninas. A disparidade do número de egressos deve-se a uma série de fatores, entre eles o tamanho dos municípios atendidos pelas CFRs, o ano de fundação de cada CFR e a conjuntura específica de cada uma, particularmente no que se refere a problemas que podem implicar restrições no número de vagas.

A predominância da formação de meninos, contudo, não se repete na CFR de Bom Jesus do Sul, que vem historicamente formando 
mais meninas que meninos. Nas demais, segundo depoimentos das equipes de trabalho das CFRs, as maiores dificuldades no atendimento às meninas consiste no fato de o regime de internato (uma semana na CFR e outra na família, e assim sucessivamente), "assustar" muitos pais que dizem não sentir-se à vontade para deixar suas filhas junto com meninos. Outro motivo apontado é que, na opinião dos entrevistados, as meninas não tendem a desenvolver os conhecimentos técnicos adquiridos na CFR, influenciadas pelo contexto familiar e social, em que o trabalho da mulher agricultora, em geral, é visto como acessório ou secundário vinculado "as coisas da casa”, como já apontava a pesquisa realizada por Martinelli e Corona (2007). Além disso, segundo os mesmos depoimentos, a migração campo/cidade tem sido maior das meninas, que se empregam em geral como domésticas.

Em relação à infraestrutura, as construções são quase todas de alvenaria, sendo apenas as casas familiares de Coronel Vivida e de Santa Izabel do Oeste mistas (madeira e alvenaria); o tamanho das casas varia de 300 a $800 \mathrm{~m}^{2}$; todas estão em bom estado de conservação; todas têm luz elétrica e telefone e acesso à água tratada. Os dormitórios são separados em ala feminina e masculina, em geral com beliches que abrigam em torno de oito a dez alunos por dormitório.

Todas as CFRs possuem horta para o consumo, com diferenças no tamanho e variedade de culturas. No que se refere aos alimentos, a origem deles é quase que exclusivamente das famílias dos alunos, de instituições publicas (merenda escolar) ou proveniente de doações da própria comunidade.

Quanto ao corpo docente, as 16 CFRs participantes da pesquisa contam com 120 profissionais, dentre professores e monitores. Destes, 69 docentes, entre monitores e professores de ambos os sexos, participaram voluntariamente da pesquisa. Portanto, os dados a seguir são relativos a essa amostra, a qual foi considerada pelos pesquisadores bastante representativa por corresponder a 57,50\% da população visada.

No que diz respeito ao sexo, há uma inversão nas proporções quando se compara o tipo de atuação na pedagogia da alternância. Os 
monitores são predominantemente do sexo masculino (70,83\%), ao passo que os professores são predominantemente do sexo feminino (71,11\%). Esse dado chama a atenção se considerarmos que a natureza da atividade de ambos os grupos é a mesma. Como é de conhecimento amplo, a docência como área de atuação profissional na educação escolar em geral é predominantemente feminina. Por outro lado, os dados sugerem que a docência nas CFRs do sudoeste do Paraná, no tocante às disciplinas típicas da área agrícola - aquelas ministradas pelos monitores -, é área de atuação com predominância masculina.

Esse dado chama a atenção porque, se por um lado contrasta com o universo feminino da docência em geral; por outro, parece refletir tanto a diferença significativa entre o número de meninos e o de meninas nas CFRs quanto o próprio mercado de trabalho para profissionais da área das ciências agrárias, que prefere empregar mais homens que mulheres.

Levando-se em conta a área e o nível de formação, entre os professores, todos são graduados nas diversas licenciaturas, sendo um deles mestre em Educação. Já quanto aos monitores, identificamos 13 graduados distribuídos nas áreas de Agronomia, Veterinária, Nutrição, Administração, Zootecnia e Pedagogia. Os demais têm formação profissional de nível médio em agricultura, agropecuária e agroecologia. Dentre esses, há apenas um sujeito do sexo feminino.

Novamente, esses dados parecem refletir a divisão dos sexos nos cursos de formação profissional de nível médio para a área agrícola em todos os tipos de escola, os quais são mais frequentados por jovens do sexo masculino. Essa inferência é corroborada, inclusive, pela proporção verificada entre meninos e meninas nas CFRs pesquisadas apresentadas anteriormente.

Já quanto à formação superior, das sete mulheres que atuam como monitoras, apenas uma não tem esse nível. As demais são graduadas em Agronomia (2), Nutrição (1), Veterinária (1), Administração (2). Portanto, considerando esse nível de formação, não há diferença significativa entre os sexos, embora se perceba ligeira predominância feminina. 
Os sujeitos do sexo masculino que são monitores são graduados em Pedagogia (1), Zootecnia (1) e Agronomia (3).

Esses dados, como já o dissemos, refletem o mercado de trabalho. Mas, por outro lado, para as mulheres egressas dessas áreas, os dados sugerem também que a monitoria nas CFRs do sudoeste do Paraná aparece como uma opção de trabalho, pelo menos até que se consiga colocação mais bem remunerada, haja vista o fato de que duas das sete monitoras têm entre dois meses e um ano de experiência na função.

Em suma, dentre os monitores de nível médio quase a totalidade é masculina, ao passo que entre os de nível superior há ligeira predominância feminina. Uma observação pode ser feita a respeito: no caso feminino, o que parece emergir da pesquisa é a docência como campo de trabalho para egressas das áreas agrárias, o que, por sua vez, compatibiliza com a predominância feminina na educação escolar básica em geral.

Considerando que as 16 CFRs do sudoeste do Paraná pesquisadas foram criadas há mais de dez anos, chama a atenção o tempo médio de experiência dos monitores e professores com a pedagogia da alternância, ainda que estes tenham, em média, o dobro do tempo de experiência daqueles.

Dentre os 24 monitores, considerando os dois sexos, apenas oito têm seis ou mais anos de experiência, dos quais cinco têm formação de nível superior. Os demais 16 monitores têm entre dois meses e três anos de experiência na função.

Dentre os professores o quadro é mais preocupante. Dentre os 45 docentes, considerando ambos os sexos, apenas um tem 12 anos de experiência em CFR e outro tem sete anos. Todos os demais variam entre um mês e quatro anos de experiência com a pedagogia da alternância, sendo esses últimos, no entanto, apenas quatro docentes.

Esses dados corroboram informações que obtivemos em entrevistas que realizamos com coordenadores quanto à alta rotatividade de monitores e professores nas CFRs da região sudoeste.

No que diz respeito aos monitores, o problema tem a ver com os baixos salários e com as dificuldades que a Arcafar/Sul enfrenta para 
mantê-los em dia. Assim, a monitoria na pedagogia da alternância parece surgir como alternativa de trabalho para jovens egressos da área das ciências agrárias somente enquanto não encontram trabalhos mais bem remunerados.

Por sua vez, quanto aos professores o problema não é tanto o da remuneração, pois esses profissionais são pagos pelo governo do Paraná. Nas entrevistas que realizamos com coordenadores e professores das CFRs, parecem emergir, principalmente, dois fatores para a alta rotatividade desses profissionais: em primeiro lugar, trata-se de que a maioria dos professores tem vínculo empregatício precário. Isto é, que não foram contratados mediante concurso público; em segundo lugar, os professores do quadro permanente do magistério relutam em aceitar aulas nas CFRs porque, segundo informou um entrevistado, eles perdem alguns privilégios, tais como a possibilidade de trabalhar 20 horas extraordinárias e, ao fim de um mês, receber por 60 horas semanais de trabalho. Além disso, os professores do quadro permanente não se dispõem a fazer algumas atividades típicas do método da alternância, como, e principalmente, ir às propriedades rurais acompanhando os monitores nas visitas às famílias dos alunos.

Reside aí, portanto, a explicação para a aparente contradição entre o privilégio de se ter poucos alunos - com os quais é possível atuar quase que de modo personalizado - e a pouca aceitação por parte dos professores das CFRs como campo de trabalho. Na verdade, a dedicação exclusiva implica significativa perda salarial, por um lado; e, por outro, exige do professor o cumprimento de tarefas para os quais muitos não foram preparados, ou preferem não executar.

\section{Concluindo: sobre o desempenho escolar dos estudantes das CFRs do sudoeste}

Apesar da situação privilegiada em que se encontram, os alunos das CFRs do sudoeste em comparação com os estudantes urbanos no que se refere ao tamanho das turmas, ao número de professores e à 
dedicação exclusiva do corpo docente, a maioria dos participantes da pesquisa disse não observar diferenças significativas para maior no rendimento acadêmico dos alunos. Esse fato chama a atenção, principalmente se levarmos em conta a dedicação exclusiva do docente e o atendimento quase personalizado que os jovens das CFRs do sudoeste paranaense têm à disposição da parte de professores e monitores. Essa questão, no entendimento dos autores deste trabalho, merece o desenvolvimento de estudos aprofundados.

Além disso, se por um lado a dedicação exclusiva dos professores é um dado altamente positivo; por outro, não se pode dizer o mesmo a respeito do processo de seleção e permanência dos docentes que atuam nas CFRs. Na época de atribuição de aulas, no início de cada ano letivo, o setor responsável nos Núcleos Regionais de Educação divulga vagas para as CFRs e entrevista os professores interessados. Ocorre que, apesar do aparente privilégio de atuar em poucas turmas com no máximo 25 alunos em cada uma e em regime de dedicação exclusiva, são poucos os professores do quadro permanente do magistério que procuram trabalhar nas CFRs pelos motivos apontados anteriormente.

Assim, parte bastante significativa dos docentes das CFRs, por não pertencer ao quadro permanente do magistério do Paraná, não tem estabilidade assegurada, de forma que a cada ano, em função do processo de atribuição de aulas, pode ocorrer mudança total ou quase total no quadro dos professores em determinada casa. Como exemplo, citamos o caso da CFR de Pato Branco, em que apenas uma docente que lecionava nessa instituição no ano letivo de 2009 continuou em 2010.

Por isso, em que pese o fato de que a alocação do pessoal docente exclusivamente em uma CFR permita aos professores excelentes condições para planejarem e executarem o trabalho pedagógico com os monitores, a alta rotatividade tanto de professores quanto de monitores dificulta sobremaneira a criação de quadros docentes bem familiarizados com o método pedagógico da alternância.

Por outro lado, no sentido oposto ao que foi dito acerca do desempenho acadêmico dos jovens das CFRs, há unanimidade entre 
professores, monitores e familiares quanto às significativas diferenças de atitude em relação ao estudo e ao comportamento de modo geral entre os jovens das CFRs e os jovens das escolas urbanas.

A esse respeito, em nossa pesquisa obtivemos relatos enfáticos que davam conta do impacto altamente positivo que a convivência na CFR tem na vida do adolescente. Familiares, professores e monitores observam que muitos desses jovens desenvolvem rapidamente senso de independência e interesse por questões comunitárias; mães informaram, por exemplo, que seus filhos e filhas começam a se interessar inclusive por questões cotidianas da gestão do lar e da propriedade, fato esse que não observam em seus outros filhos e filhas que só estudam em escolas urbanas.

Os pesquisadores também observaram diferenças em certos aspectos do comportamento nos jovens das CFRs pesquisadas em relação ao comportamento dos jovens de escolas urbanas. Notou-se, por exemplo, muito rapidamente certa polidez, gentileza mesmo, no trato com os demais, curiosidade e extroversão. Alguns docentes da CFR de Pérola do Oeste afirmaram que a diferença no comportamento no ambiente escolar dos jovens rurais é tão marcante em relação ao comportamento no ambiente escolar dos jovens urbanos, que eles - professores - nem se imaginam mais atuando em outros tipos de escola.

Em visita realizada a uma família produtora de leite no município de Enéas Marques, testemunhamos o que pareceu um grande afeto presente na relação entre a monitora que nos acompanhava e a família que nos recebia em sua propriedade. De fato, parecia que se tratava de parentes próximos, embora não o fossem, tal o grau de intimidade aparente. Nesse caso específico, a família tem uma filha que frequentou a CFR e hoje, já casada, tem emprego urbano no comércio da cidade de Enéas Marques. A filha mais jovem do casal, de apenas 12 anos, frequenta a $6^{\mathrm{a}}$ série na CFR e disse gostar tanto da escola que já estava achando as férias muito prolongadas.

O pai da jovem disse que, em princípio, achava que a criação da CFR no município era apenas mais uma atividade do poder público para 
dar "emprego ao povo" e que apenas concordou que sua filha mais velha fosse estudar lá porque ela se informara e ficara interessada. Contudo, não demorou, afirmou, para que notasse que não se tratava de uma escola comum e que, embora sua filha mais velha não atue na agricultura, o que aprendeu abriu-lhe oportunidades no mercado de trabalho.

Ainda obtivemos vários relatos de pais que disseram que após certo tempo na CFR seus filhos querem participar de modo mais ativo na gestão e na execução do trabalho, no sentido de querer exercitar as técnicas que aprendem. Não é incomum, também, mães contarem que os adolescentes querem espaço e liberdade para plantar hortaliças e frutas, cujos produtos, depois, são usados na alimentação da própria família e, em muitos casos, são levados à CFR como contribuição para a manutenção da entidade.

Enfim, ao que parece, as casas familiares rurais se consolidaram como uma excelente alternativa para a educação escolar dos filhos de pequenos agricultores na região sudoeste do Paraná. Todavia, essas instituições sofrem com questões de natureza administrativa que dificultam muito a manutenção de um corpo docente estável, seja em função das dificuldades relacionadas ao vínculo precário da maioria dos professores da rede estadual que atuam nessas escolas, seja em função da rotatividade dos monitores causada por questões salariais. Questões tais que, uma vez bem encaminhadas, talvez repercutam positivamente no desempenho acadêmico dos estudantes, diferenciando-os positivamente do desempenho dos estudantes do meio urbano que não têm o privilégio de estudar em turmas pequenas e com professores e monitores que podem prestar um atendimento quase personalizado.

\section{Agradecimento}

Os autores agradecem ao Conselho Nacional de Desenvolvimento Científico e Tecnológico (CNPq) pelo auxílio financeiro concedido à pesquisa. 


\section{Referências}

BEGNAMI, J. B. Pedagogia da alternância como sistema educativo. Revista da Formação por Alternância, n. 2, p. 24-47, 2006.

BRASIL. Lei n. 9.394/96, de 20 de dezembro de 1996. Estabelece as diretrizes e bases da educação nacional. Diário Oficial [da] República Federativa do Brasil, Poder Legislativo, Brasília, DF, 23 dez. 1996. p. 27833. Disponível em: <http:// www6.senado.gov.br/legislacao/ListaTextoIntegral.action?id=75723〉. Acesso em: 23 nov. 2010.

GIMONET, J. C. Nascimento e desenvolvimento de um movimento educativo: as casas familiares rurais de educação e orientação. In: SEMINÁRIO INTERNACIONAL DA PEDAGOGIA DA ALTERNÂNCIA: ALTERNÂNCIA E DESENVOLVIMENTO, 1., 1999, Salvador. Anais... Salvador: UNEFAB, 1999. p. 39-48.

GOWACKI, C.; BERNARTT, M. L.; TEIXEIRA, E. S. Casa familiar rural e pedagogia da alternância: alternativa teórico-metodológica adequada para a educação do campo. In: SEMINÁRIO EDUCAÇÃO E DESENVOLVIMENTO, 1., 2007, Pato Branco. Anais... Pato Branco: CEPAD/UTFPR, 2007.

MARTINELLI, G.; CORONA, H. M. P. Considerações sobre gênero na formação de rapazes e moças na casa familiar rural de Sulina - PR. In: SEMINÁRIO EDUCAÇÃO E DESENVOlVIMENTO, 1., 2007, Pato Branco. Anais... Pato Branco: CEPAD/UTFPR, 2007.

PARANÁ. Decreto n. 3.106/94, de 14 de março de 1994. Cria o Programa de Apoio às Casas Familiares Rurais. Diário Oficial do Estado. Poder Executivo, Curitiba, PR. 18 mar. 1994. Disponível em:<http//www.paranacidade.org.br/ pdf/fdu/.../decreto_n3106_14-03-94.pdf >. Acesso em: 7 out. 2010.

SILVA, L. H. da. Modalidades, representações e práticas de alternância na formação de jovens agricultores. Revista da Formação por Alternância, n. 2, p. 5-23, 2006. 
TEIXEIRA, E. S.; COSTA, D.; PERUZZO, M. A pedagogia da alternância e a modelagem matemática: aproximações de propósitos? Espaço Pedagógico, v. 14, p. 56-68, 2007.

TEIXEIRA, E.; BERNARTT, M.; TRINDADE, G. A. Estudos sobre pedagogia da alternância no Brasil: revisão de literatura e perspectivas para a pesquisa. Educação e Pesquisa, v. 34, n. 2, p. 227-242, 2008.

Recebido: 13/01/2011

Received: 01/31/2011

Aprovado: 25/01/2011

Approved: 01/25/2011 